\title{
ПОСТИНДУСТРИАЛЬНОЕ ОБЩЕСТВО: СТРУКТУРА, ПРИЗНАКИ, МЕХАНИЗМ И ЗАКОНОМЕРНОСТИ ФОРМИРОВАНИЯ
}

\author{
О.В. ДОМАКУР
}

доцент кафедры менеджмента и экономики социальной сферы

Белорусского государственного университета, г. Минск

\begin{abstract}
Аннотация
В исследовании представлень основные положения теории постиндустриального общества, ее методология, определение термина, критерии и признаки трансформациии общества от доиндустриального, индустриального к постиндустриальному обществу, определен механизм и сформулированы закономерности формирования постиндустриального общества.
\end{abstract}

Ключевые слова: постиндустриальное общество, формирование постиндустриального общества, трансформация общества, теория, методология,.

\section{Abstract}

The study presents the main points of the theory of post-industrial society, its methodology, the definition of criteria and features of the transformation of society from a preindustrial, industrial to post-industrial society, defined the mechanism and formulated the laws of formation of post-industrial society.

Key words: post-industrial society, formation of post-industrial society, transformation of society, theory, methodology.

\section{ВВЕДЕНИЕ}

Вопросы, возникающие по поводу формирования постиндустриального общества, остаются актуальными на протяжении нескольких десятилетий в кругу аналитиков разных областей науки и практики. В статье представлены отдельные результаты длительного научного поиска и предложены ответы на такие вопросы как: что такое постиндустриальное общество, каковы его признаки, как оно формируется и как можно оценить уровень его развития.

Постиндустриальное общество пришло на смену индустриальному вследствие внедрения в промышленное и сельскохозяйственное производство автоматизированной техники и информационных технологий, в результате повысилась производительность труда и началась экспансия сферы услуг в структуре ВВП и занятости. Новая технологическая база способствовала интеллектуализации труда и потребовала повышения уровня образования работников. Эффективное массовое производство индустриальной эпохи создало материальную базу для повышения значимости таких сфер деятельности как наука, образование, здравоохранение, отражающих уровень благосостояния граждан и качество социально-экономического роста. В настоящее время в ряде стран Запада сформировалось постиндустриальное общество. Республика Беларусь, являясь частью мирохозяйственной системы, также ставит цели по формированию основ постиндустриального общества с новым технологическим базисом $[2$, c. 32] и к постиндустриальному обществу и инновационному развитию экономики [3, с. 4]. Это свидетельствует о необходимости развития теории постиндустриального общества и разработки концептуального подхода к совершенствованию политики модернизации белорусской экономики для достижения поставленных целей. 


\section{РЕЗУЛЬТАТЫ И ИХ ОБСУЖДЕНИЕ}

Вопросы методологии. Теория постиндустриального общества имеет многолетнюю историю своего развития с периодами популярности и забвения. С момента появления данная концепция считалась футурологической, поэтому некоторые исследователи предлагали собственное видение развития событий (посткапиталистическое общество, постбуржуазное общество, постиндустриальный капитализм), а другие оставались приверженцами и защитниками индустриального (или неоиндустриального) общества. Однако в конце XX века проявившиеся признаки трансформации общества в развитых странах, особенно по сравнению с состоянием переходных стран бывшей социалистической системы, направили научное сообщество на анализ происходящих изменений. В этой связи актуальность темы возросла, увеличилось и количество научных, научнопублицистических публикаций и диссертационных исследований на данную тему.

Проведенный анализ показал, что: 1) научный поиск по данной теме концентрируется на каком-то одном аспекте формирования постиндустриального общества, что характерно для молодых ученых, либо на расширенном философском подходе; 2) теория постиндустриального общества подвергается критике по таким направлениям, как: нечеткость, размытость понятия «постиндустриальное общество», преуменьшение роли производства товаров, упрощенный подход к выделению сферы услуг, преувеличение роли информации в создании стоимости, игнорирование проблем мирового развития, игнорирование культурно-духовного развития общества. Несмотря на большое количество критических замечаний, теория постиндустриального общества имеет право на существование и развитие, так как исследует самые современные проблемы современного изменяющего мира.

Методология теории постиндустриального общества получила свое развитие путем системного подхода к применению принципа единства исторического и логического как метода научного познания, а также дополнение позитивистского подхода нормативной составляющей. Историзм, заключающийся в применении стадийного подхода (выделение стадий развития общества - доиндустриальное общество, индустриальное общество, постиндустриальное общество, а также трех этапов формирования постиндустриального общества) и использовании осевого принципа (анализ системы отношений вдоль оси тип производства и виды используемого знания (технологий)), был дополнен эволюционным подходом (исследование причин и особенностей, выявление закономерностей постепенного перехода от индустриального к постиндустриальному обществу). Логический принцип, заключающийся в уточнении системы категорий и анализируемых проблем, был дополнен структурным анализом (исследование изменений структуры занятости, производства, расходов домашних хозяйств), индексным методом (разработка индекса развития постиндустриального общества, индекса динамики спроса и производительности труда в отраслях экономики). Развитие методологии позитивизма и усиление нормативной составляющей проявилось в том, что помимо конкретизации важнейших характеристик постиндустриального общества, выделения этапов его становления, были обоснованы социально-экономический механизм и закономерности его формирования, выявлены критерии и разработана методика оценки уровня развития постиндустриального общества в конкретной стране; разработаны концептуальный подход и практические рекомендации по совершенствованию социально-экономической политики в направлении интенсификации развития постиндустриального общества.

Определение постиндустриального общества. Постиндустриальное общество это общество, которое пришло на смену индустриальному обществу, в котором в результате внедрения достижений научно-технологического прогресса, автоматизации, информатизации производства и интеллектуализации труда изменяется технологическая структура (увеличивается охват хозяйствующих субъектов инновационными технологиями и средствами информатизации), экономическая структура (увеличивается 
доля сферы услуг в ВВП, доля занятых в сфере услуг), социальная структура (увеличивается доля работников и граждан с высшим образованием, уменьшаются расходы домашних хозяйств на потребительские цели и увеличиваются на услуги при росте подушевых доходов).

Данное определение отличается тем, что использован структурный подход, подчеркнуты причинно-следственные связи научно-технологического, экономического и социального развития, комплексно охватывает взаимосвязи и взаимопроникновения инновационно-информационных основ развития, роста интеллектуализации труда, усиления роли и значения сервисной экономики.

В таблице 1 представлены признаки доиндустриального, индустриального и постиндустриального обществ, по которым можно не только охарактеризовать каждое из них, но проследить изменения не только во внешних проявлениях, таких как структура общества и экономики, но и во внутренних факторах, оценить количественно их и качественно. Остановимся более подробно на характеристике признаков постиндустриального общества.

В постиндустириальном обществе основными средствами производства являются автоматизированная техника (роботы, компьютеры) и знания, предметами производства - информация и знания. Ведущим сектором экономики является сфера услуг, занимающаяся обработкой информации и созданием новых знаний.

Главными факторами экономического развития является наукоемкие технологии, образование работников. Труд становиться все более интеллектуальным, а главным мотивом к труду уже является не высокий доход, а возможность творческой самореализации, так как уровень дохода позволяет удовлетворить все первичные потребности человека, возникает спрос на товары комфорта и услуги. Наиболее многочисленную социальную группу в постиндустриальном обществе составляют служащие, обладающие высшим образованием.

Труд как фактор производства был самым доступным ресурсом во все времена, происходила лишь модификация его содержания в процессе эволюции технологических способов производства от физического ручного через физический механизированный к интеллектуальному.

Таблица 1 - Признаки доиндустриального, индустриального и постиндустриального обществ

\begin{tabular}{|c|c|c|c|}
\hline Признаки & $\begin{array}{c}\text { Доиндустриальное } \\
\text { общество }\end{array}$ & $\begin{array}{c}\text { Индустриальное об- } \\
\text { щество }\end{array}$ & $\begin{array}{c}\text { Постиндустриальное } \\
\text { общество }\end{array}$ \\
\hline \multicolumn{4}{|c|}{ Технологическая трансформация } \\
\hline $\begin{array}{l}\text { Средства труда: } \\
\text { материальные }\end{array}$ & $\begin{array}{l}\text { Земля, ручные ору- } \\
\text { дия труда }\end{array}$ & $\begin{array}{l}\text { Машины, денежный } \\
\text { капитал }\end{array}$ & $\begin{array}{l}\text { Автоматизированная } \\
\text { техника }\end{array}$ \\
\hline интеллектуальные & Навыки & Опыт & Знания \\
\hline общественные & Специализация труда & $\begin{array}{l}\text { Специализация и ко- } \\
\text { операция труда }\end{array}$ & Наука и образование \\
\hline Вид технологии & І рудоемкие & Капиталоемкие & Наукоемкие \\
\hline $\begin{array}{l}\text { Предметы труда: } \\
\text { материальные } \\
\text { интеллектуальные }\end{array}$ & Сырье & Энергия & Информация, знания \\
\hline \multicolumn{4}{|c|}{ Экономическая трансформация } \\
\hline $\begin{array}{l}\text { Тип производствен- } \\
\text { ной деятельности }\end{array}$ & Добыча & Изготовление & Обработка \\
\hline Ведущий сектор & $\begin{array}{l}\text { Сельское хозяйство } \\
\text { (в т.ч. добывающие } \\
\text { отрасли) }\end{array}$ & $\begin{array}{l}\text { Индустрия, перераба- } \\
\text { тывающая промыш- } \\
\text { ленность }\end{array}$ & $\begin{array}{l}\text { Сфера услуг (особенно } \\
\text { наука, образование и } \\
\text { здравоохранение) }\end{array}$ \\
\hline Тип потребления & $\begin{array}{l}\text { Продукты, удовле- } \\
\text { творяющие первич- } \\
\text { ные потребности }\end{array}$ & $\begin{array}{l}\text { Товары длительного } \\
\text { пользования }\end{array}$ & $\begin{array}{l}\text { Услуги и товары ком- } \\
\text { форта }\end{array}$ \\
\hline
\end{tabular}


Окончание таблицы 1.

\begin{tabular}{|l|l|l|l|}
\hline \multicolumn{4}{|c|}{ Социальная трансформация } \\
\hline Содержание труда & Физический ручной & $\begin{array}{l}\text { Механизированный } \\
\text { физический (рутин- } \\
\text { ные операции), ча- } \\
\text { стично интеллекту- } \\
\text { альный }\end{array}$ & Интеллектуальный \\
\hline Мотивация к труду & $\begin{array}{l}\text { Традиции и внеэко- } \\
\text { номическое принуж- } \\
\text { дение к труду }\end{array}$ & $\begin{array}{l}\text { Материальные (де- } \\
\text { нежные) стимулы }\end{array}$ & Творчество \\
\hline $\begin{array}{l}\text { Главная социальная } \\
\text { группа }\end{array}$ & Крестьяне & Рабочие & Служащие \\
\hline $\begin{array}{l}\text { Уровень образова- } \\
\text { ния }\end{array}$ & $\begin{array}{l}\text { Передача опыта в } \\
\text { рамках семьи }\end{array}$ & $\begin{array}{l}\text { Среднее общее, сред- } \\
\text { нее профессиональное }\end{array}$ & Высшее \\
\hline
\end{tabular}

Источник: собственная разработка

Комплексная автоматизация производства, создание материалов с заранее заданными свойствами, овладение новыми способами получения и преобразования энергии, передачи ее на любые расстояния, замена механических технологий на информационные способствовали интеллектуализации трудовой деятельности, развитию высшего образования, углублению его специализации.

Новый технологический этап социально-экономического развития усложняет производственные структуры и процессы, требует использования в производстве не только элементарных способностей человека к труду, но также и способности участия в научном поиске и управлении производством. В постиндустриальном обществе необходимостью становятся знания, позволяющей не только совершенствовать орудия труда или принципы организации производственной и общественной деятельности, производить товары и услуги высокого качества, но и потреблять эти товары и услуги, создавать и передавать новые знания.

Формирование постиндустриального общества сопровождается замещением массового производства высокоэффективным гибким производством, ориентированным на индивидуализированный спрос. Работник такого производства должен быть способным развивать свой творческий потенциал, не только реализуя в производстве достижения науки и техники, но и генерируя новые идеи. Основным условием эффективного функционирования современного производства является наличие работника, подготовленного к постоянным переменам технологического процесса и внедрению инноваций. В этом проявлении человек-работник выступает как двигатель научно-технологического прогресса и регулятор его приоритетов.

Этапы и механизм формирования постиндустриального общества. Первый этап становления постиндустриального общества (середина 50-х - середина 70-х гг. XX в.) характеризуется бурным индустриальным развитием и ростом сервисизации", накоплением научных знаний и постепенным внедрением их в производство товаров, ростом производительности труда и благосостояния граждан.

На втором этапе (середина 70-х — середина 90-х гг. ХХ в.) происходит информатизация производства — информационные технологии обеспечивают рост производи-

\footnotetext{
* В основе выделения этапов заложен технологический критерий. Так как постиндустриальное общество начало зарождаться на пике зрелости индустриального общества, то технологический критерий автоматизации производственного процесса не позволил увидеть зарождающиеся изменения, экономический критерий и признаки (увеличение доли сферы услуг в ВВП и занятости проявились сильнее. Дальнейшая автоматизация всех бизнес-процессов (бухгалтерия, делопроизводство, расчеты, планирование, прогнозирование, принятие решений, мониторинг и др.) приводит к появлению нового вида производственной деятельности (разработка и внедрение информационно-коммуникационных технологий), способствует ускорению обмена коммерческой информации, расширению традиционных видов услуг (связь, торговля, финансы), выделению в качестве отдельного вида коммерческой деятельности консалтинга (в том числе аутсорсинга).
} 
тельности труда и развитие новых видов деятельности. Новейшие информационные технологии внедряются в традиционное производство, снижаются материалоемкость и энергоемкость производства, повышается степень автоматизации производственных процессов.

Третьему этапу (середина 90-х гг. XX в. - начало XXI в.) присуще развитие, основанное на инновациях и всеобщей информатизации, - повышение наукоемкости производства, увеличение расходов на информационные технологии и технику, ускорение внедрения научных достижений в хозяйственную практику, обеспечение конкурентоспособности инновационной экономики.

Социально-экономический механизм перехода индустриального общества в постиндустриальное представляет собой процесс закономерной трансформации (рисунок 1). В отличие от механизма регулирования он не предполагает определение инструментов и направлений их воздействия на конечный параметр, а представляет элементы и процессы трансформации, их взаимное влияние друг на друга и результаты.

С целью повышения эффективности (рост ставок заработных плат, экологических стандартов, усиление ценовой конкуренции) предприниматели стремились внедрить новое автоматизированное оборудование и технологии для ускорения обмена информацией и принятия управленческих решений, что способствовало росту производительности труда и сокращению необходимого количества занятых в промышленности.

В тоже время повышение материального богатства всех слоев общества привело к расширению спроса на разнообразные виды услуг и стимулировало рост предложения услуг, что проявилось в увеличении доли сферы услуг в ВВП и занятости. Новые технологии и расширение сфер межличностного общения потребовали нового качества трудовых ресурсов, повышения уровня образования и постоянного его развития. Так сформировались три основных элемента постиндустриального общества: информационное общество (как технологический фундамент), сервисная экономика (как сфера повышения качества жизни) и общество знаний (новая система стратификации).

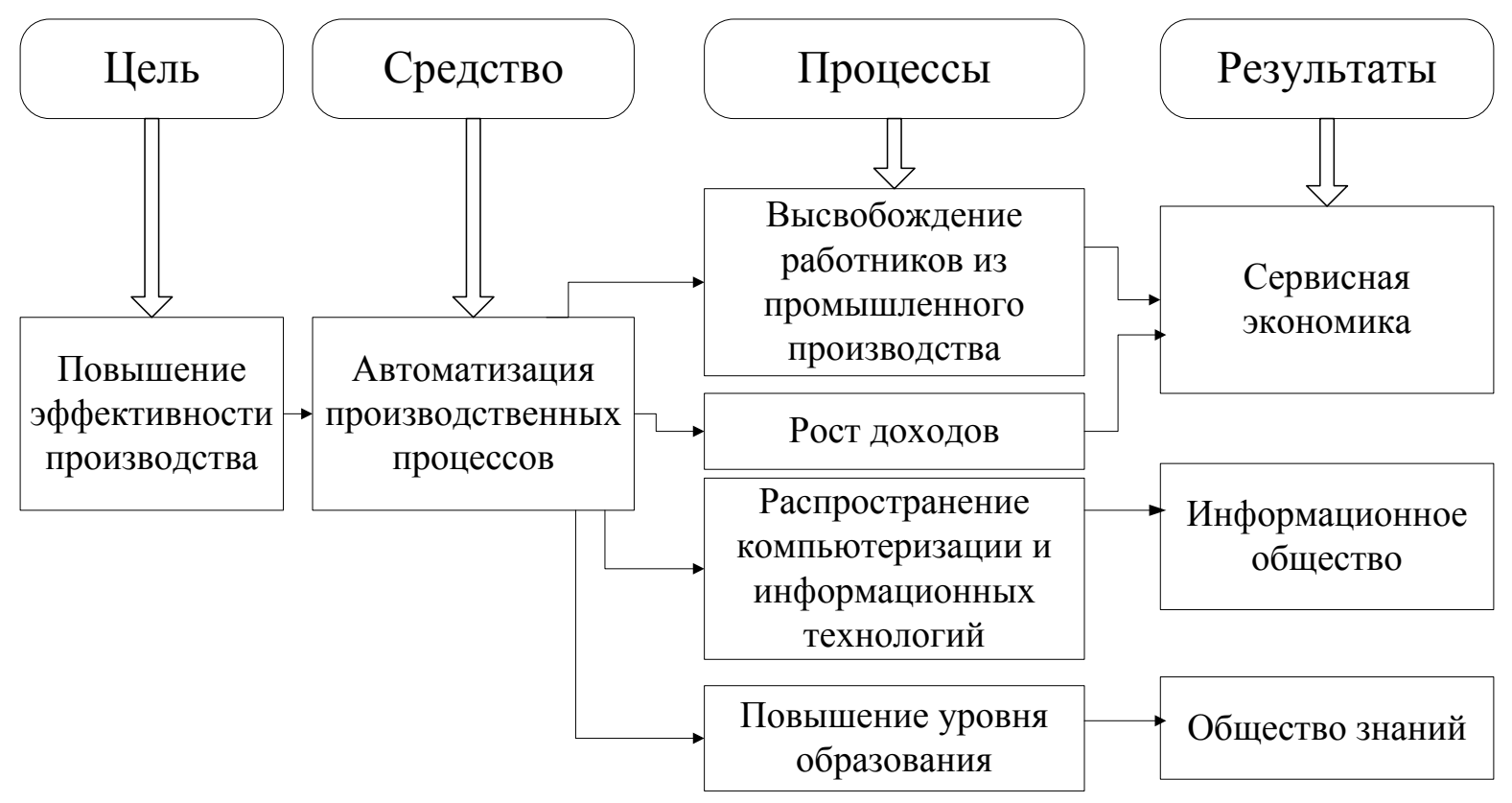

Рисунок 1 - Социально-экономический механизм трансформации индустриального общества в постиндустриальное

Источник: собственная разработка 
Таким образом, технологическая трансформация производства приводит к структурным изменениям в экономике и обществе. Внедрение достижений научнотехнологического прогресса способствовало, с одной стороны, снижению зависимости производства от большой численности работников, т.к. их заменили автоматизированные механизмы и системы управления, с другой стороны, от оставшихся работников требовался более высокий уровень образования для эффективного контроля за технологическим процессом. Высвободившиеся из материального производства работники оказались востребованными в сфере услуг, расширению которой также способствовал рост доходов всех граждан. Сама сфера услуг достаточно быстро стала информациоёмкой и знаниеёмкой, в связи с изменением технологических основ промышленного и сельскохозяйственного производства. Соответственно, все более востребованными становились работники с высшим образованием, способные использовать новейшие информационные технологии в производстве товаров, оказании услуг и потреблении новых благ. Все это проявилось в увеличении доли сфере услуг в структуре занятости и ВВП, т.е. произошла трансформация структуры экономики направлении ее сервисизации. Кроме того, изменилась и социальная структура общества, в которой увеличилась доля работников с высшим образованием, начало формироваться общество знаний. Технологическая трансформация способствовала структурной трансформации экономики и общества.

Закономерности формирования постиндустриального общества. Трансформация экономической структуры и формирование постиндустриального общества проходило в развитых странах в соответствии со следующими закономерностями:

1) снижение доли сельского хозяйства и промышленности в структуре занятости и объемах производства за счет опережающего роста производительности труда благодаря внедрению научно-технологических достижений по сравнению с сокращающимся приростом спроса на продукты питания и замедлением роста спроса на промышленные товары вследствие приближения к физическим пределам потребления;

2) рост доходов в экономике и изменение структуры потребления в направлении увеличения доли расходов на услуги приводят к опережающему приросту спроса на услуги по сравнению с приростом производительности труда в этом секторе, так как существуют ограниченные возможности роста производительности труда в сфере услуг, что обусловливает экспансию сферы услуг;

3) высокие темпы роста спроса на услуги в связи с ростом доходов способствуют росту относительных цен на услуги и соответственно увеличению доли сектора в ВВП. В то же время снижение относительных цен на сельскохозяйственную и промышленную продукцию приводит к сокращению этих секторов в структуре ВВП. В реальном выражении объем производства промышленности и сельского хозяйства, достигнув определенного предела, стабилизируется, но его доля уменьшается, так как рост реального ВВП происходит в большей степени за счет роста сферы услуг.

Основными силами взаимодействия и изменений в рыночной экономике являются спрос и предложение. Именно они, а также неценовые факторы, взаимодействуя в течении длительного периода влияли на структуру экономики, заставляли ее эволюционно трансформироваться. Со стороны спроса - это изменение уровня дохода $(\Delta D)$, со стороны предложения изменение производительности труда $(\Delta y)$. В силу действия за- 
кона Энгеля* и внедрения достижений научно-технологического прогресса происходят изменения в соотношении прироста спроса и прироста производительности в различных секторах, что влияет на их роль в экономике. На рисунке 2 представлены закономерности и соотношение факторов трансформации структуры экономики в рамках трехсекторной модели, где $\beta$ - доля занятых в секторе, $Z$ - доля сектора в ВВП, $\Delta L-$ изменение занятости, $\triangle P$ - изменение уровня цен. На рисунке 3 можно увидеть динамику соотношения всех величин по мере прохождения трех основных фаз развития каждым сектором.

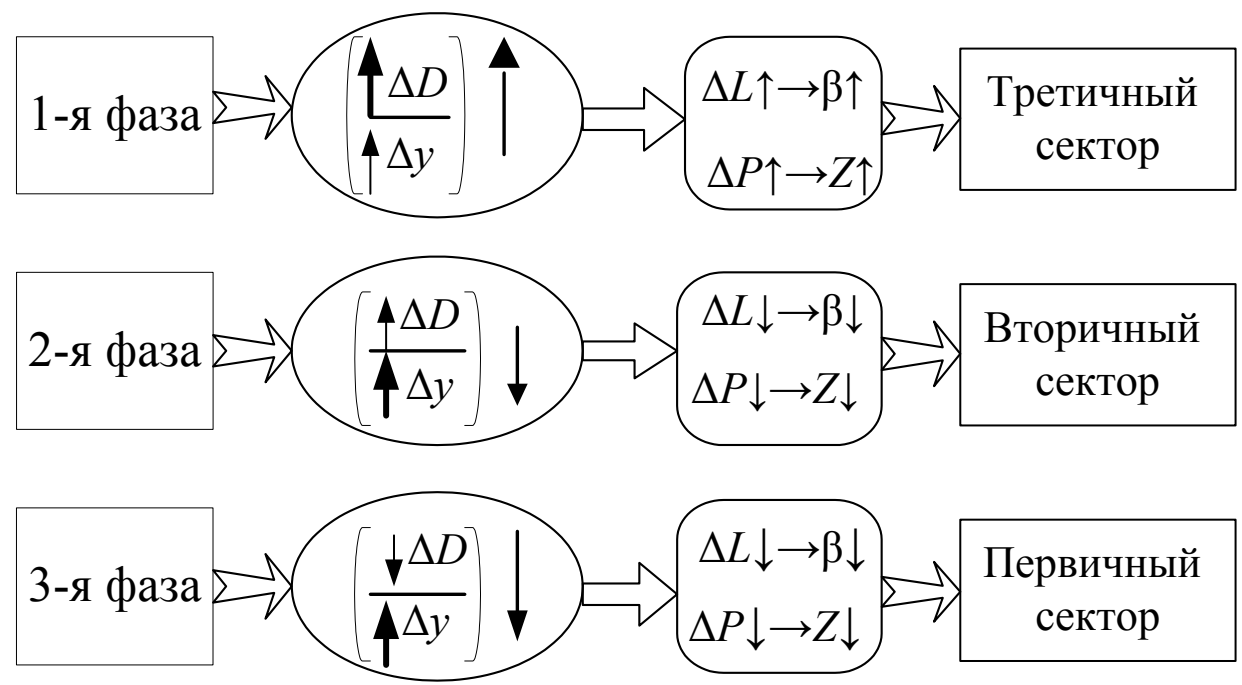

Рисунок 2 - Трансформация структуры экономики

Источник: собственная разработка

По мере роста доходов в силу действия закона Энгеля в структуре расходов населения снижается доля средств, направляемых на продукты питания, и увеличивается доля товаров промышленного производства и услуг. В начале становления индустриального общества прирост спроса на продукты промышленного производства должен опережать прирост производительности, а затем по мере замедления темпов роста спроса в силу достижения физических пределов насыщения производительность растет быстрее, что в итоге приводит к высвобождению работников из промышленности. В то же время, продолжающийся рост доходов способствует значительному росту спроса на услуги, поэтому сектор услуг расширяет свои масштабы и увеличивает занятость, так индустриальное общество переходит в новую форму - постиндустриальное общество.

\footnotetext{
* Закон Энгеля - закон экономики, согласно которому поведение потребителей связано с размером получаемого ими дохода, и по мере роста доходов потребление населением благ возрастает непропорционально. Расходы на питание возрастают в меньшей степени, чем расходы на предметы длительного пользования, путешествия или сбережения. А структура потребления продуктов питания изменяется в сторону более качественных продуктов. Рост доходов приводит к увеличению доли сбережений и потреблению высококачественных товаров и услуг при сокращении низкокачественных. На основе формулы эластичности спроса по доходам подсчитано, что в конце 1980-х гг. в США с ростом дохода на $1 \%$ спрос на продукты питания возрастал на $0,77 \%$, на одеж-ду - на $0,32 \%$, на транспортные средства - на $1,1 \%$, на жилище - на $0,89 \%$, на медицинские услуги - на $1,9 \%$, на предметы роскоши - на $3,6 \%$, на спортивные товары - на 3,7\%, на услуги такси - на 2,8\%.
} 


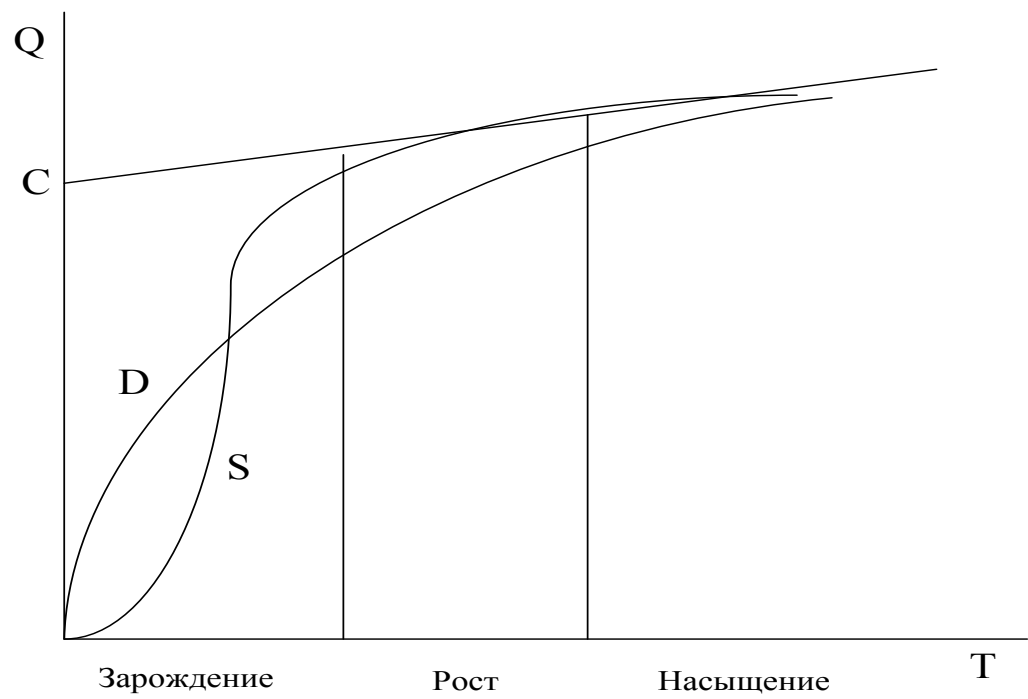

Рисунок 3 - Динамика спроса и предложения по стадиям эволюции сектора Источник: [1, с. 168]

Рост производительности в промышленности обусловлен возможностями физической стандартизации производства товаров, организации массового производства, современные технологии позволяют организовать не менее эффективное серийное или единичное производство. В то же время заметного ускорения производительности труда в услугах на данном этапе не произойдет, так как их предоставление требует физического участия человека.

Достижение высокого экономического роста и уровня жизни исключительно за счет развития сферы услуг для стран, стремящихся к созданию постиндустриального общества, сопровождается следующими трудностями:

- темпы роста производительности труда в сфере услуг значительно ниже, чем в промышленности, соответственно темпы экономического роста и уровня жизни замедляются;

- недостаточная конкурентоспособность промышленного производства приводит к проблемам с платежным балансом, а экспорт услуг ограничен из-за небольшого перечня «торгуемых позиций» и невысокой их конкурентоспособности на мировом рынке;

- расширение сектора услуг и повышение их качества должно происходить внутри страны за счет увеличения спроса на них другими секторами экономики, а также при возрастании спроса на них со стороны конечных потребителей.

\section{ВЫВОДЫ}

Результатом данного исследования является развитие и обогащение теории постиндустриального общества в таких направлениях, как развитие ее методологии, конкретизация термина, критериев и признаков трансформации общества от доиндустриального, индустриального к постиндустриальному обществу, определение механизма и формулировка закономерностей формирования постиндустриального общества.

Формирование постиндустриального общества является закономерным и эволюционным процессом интеллектуального развития человеческого потенциала развитых стран и способность использовать результаты научных достижений в направлении улучшения условий жизни большей части населения постиндустриальных стран. Качество жизни в таких странах не ухудшается несмотря на замедление темпов экономического роста, периодичность кризисов и значительной дифференциации доходов, при этом они все меньше зависят от ресурсов, ранее поставляемых из менее развитых стран, но все больше зависят от творческого потенциала ученых и предпринимателей. 


\section{ЛИТЕРАТУРА}

1. Кликич, Л.М. Эволюция сферы услуг: особенности, закономерности, формы государственного регулирования : дис. ... д-ра экон. наук: 08.00.01 / Л.М. Кликич. Уфа, 2006. - 311 л. - [Электронный ресурс]. - 2005. - Режим доступа: http://diss.rsl.ru/diss/05/0702/ 050702040.pdf. - Дата доступа: 16.08.2007

2. Национальная стратегия устойчивого социально-экономического развития Республики Беларусь на период до 2020 г. / Национальная комиссия по устойчивому развитию Респ. Беларусь; Редколлегия: Я.М. Александрович и др. - Мн.: Юнипак. 200 с. [Электронный ресурс]. - Режим доступа: http://un.by/pdf/OON_sMall_Rus.pdf. Дата доступа: 25.05.2015.

3. Национальной стратегии устойчивого социально-экономического развития Республики Беларусь до 2030 года. ГНУ НИЭИ Министерства экономики Республики Беларусь. Минск, 2015 [Электронный ресурс]. - Режим доступа: srrb.niks.by/info/ program.pdf. - Дата доступа: 12.05.2015.

Статья поступила в редакцию 25 ноября 2015 года. 